\title{
Retraction Note to: Coastline land use planning and big data health sports management based on virtual reality technology
}

\author{
Jianrong Pang ${ }^{1} \cdot$ Xinrong $\mathrm{Li}^{1} \cdot$ Xiaoyun Zhang ${ }^{1}$
}

Published online: 9 November 2021

C) Saudi Society for Geosciences 2021

Retraction Note to: Arabian Journal of Geosciences (2021) 14: 1080 https://doi.org/10.1007/s12517-021-07415-6

The Editor-in-Chief and the Publisher have retracted this article because the content of this article is nonsensical. The peer review process was not carried out in accordance with the Publisher's peer review policy. Author Jianrong Pang has not responded to correspondence regarding this retraction. The publisher has not been able to obtain a current email address for authors Xinrong Li and Xiaoyun Zhang.

The original article can be found online at https://doi.org/10.1007/ s12517-021-07415-6.

Jianrong Pang

pangjianrong8332@163.com

1 Changji College, Changji 831100, Xinjiang, China 